\title{
On the Curriculum Setting of College Oral English Course Based on Prefabricated Chunk Theory and Input and Output Strategies
}

\author{
Guoting Qian ${ }^{a}$, Yixuan Duan ${ }^{\mathrm{b}, *}$ \\ School of Foreign Languages, Wuhan University of Technology, Wuhan 430070, China \\ aqianguoting@whut.edu.cn, byxduan@whut.edu.cn
}

\begin{abstract}
Nowadays, spoken English teaching in China on the improvement of students' oral ability does not meet the expectation. "Dumb English" is still prominent in English-language learners. This paper develops a research using questionnaire survey on students' spoken abilities and needs. An efficient curriculum setting is put forward by combining chunk theory with input and output strategies. It consists of accumulative input, collaborative dialogue and automatic output. As the desired outcome of the curriculum setting, the automaticity in the third part can facilitate the fluency of learners' spoken English.
\end{abstract}

Keywords: prefabricated chunk theory, oral English course, input, output, college students.

\section{Introduction}

\subsection{Prefabricated Chunk Theory}

\subsubsection{Definition}

Chunk is a language structure that combines the features of both vocabulary and grammar; it performs a specific language function in the form of several words customarily used together in a fixed expression.

\subsubsection{Development}

The appearance of the term of "prefabricated chunk" can be traced back to the 1970s, when Becker [1] and Bolinger [2] initially proposed it. In the book "Lexical Phrases and Language Teaching" published in 1992, Nattinger and DeCarrico classified prefabricated chunks into ploy-words, institutionalized expressions, phrasal constraints, and sentence builders according to the structure prefabricated chunks [3]. In the 1990s, Michael Lewis categorized prefabricated chunks into poly-words, high frequency collocations, fixed expressions and semi-fixed expressions [4]. Nowadays, a growing number of scholars and experts try to further study on prefabricated chunk from the perspective of psycholinguistics and it into practices.

\subsection{Input and Output Strategies}

In an instructional setting, input has been characterized as having communicative intent [5] and output is depicted as meaningful production of language [6]. Stephen Krashen put forward the input hypothesis which states that "comprehensible input" of the second language learner contribute to the acquisition of a second language [7]. In the "output hypothesis", Merrill Swain states that through producing language, either spoken or written, language acquisition/learning may occur [8]. Although different voices are heard when input and output are compared, the fact that both of them are methods of second language acquisition is undeniable.

\subsection{Prefabricated Chunk and the Teaching of Spoken English}

English, as the most widely learned second language worldwide, also enjoys Chinese people's enthusiasm for learning. However, the fluency and accuracy in spoken English are hard to realize. In the course of searching for solutions, application of prefabricated chunk in the acquisition of a second language gradually attracts the attention of linguistics and educators. Altenberg states that "roughly $70 \%$ of the running word in the London-Lund corpus form part of recurrent word combinations of some kind" [9]. Applying scientific input and output strategies of prefabricated chunk into the practice of spoken English can reduce the processing time and improve the fluency and accuracy. 


\section{Curriculum Setting on Oral English Course based on Prefabricated Chunk Theory and Input and Output Strategies}

\subsection{Empirical Research of Curriculum Setting on Oral English Course}

1. Survey method: e-questionnaires

2. Respondent: college students throughout the country

3. Survey Objective:

Analysis on students' current spoken abilities and needs

4. Survey Scope:

200 e-questionnaires were sent to several colleges, different majors. 175 were recycled.

5. Conclusion:

Seventy-five percent of students dare not open their month due to grammar, vocabulary or pronunciation deficiency. About $87 \%$ participants dissatisfy with their learning environment. Under the pressure of "silence" atmosphere, $20 \%$ students are unwilling to speak. Besides, speaking to classmates is comfortable for 53\% learners. Fifty percent of students are fund of reading, reciting, group discussing and performing to practice spoken English.

"Using chunk theory to give learners a bit amount of chunk input can improve the accuracy, fluency, coherence and authenticity of learners' oral English [10]." The implement of chunk language encourages learners to speak. Creating a supportive learning atmosphere and maximizing opportunities for output are also effective to ease the poor performance in oral communication.

\subsection{The Design of Curriculum Setting on Oral English Course Based on Prefabricated Chunk \\ Theory and Input and Output Strategies}

The curriculum model of college oral English course based on prefabricated language chunk is divided into three parts. They are Accumulative Input, Collaborative Dialogue and Automatic Output. The sketch of the oral English course model is shown in Figure 1.

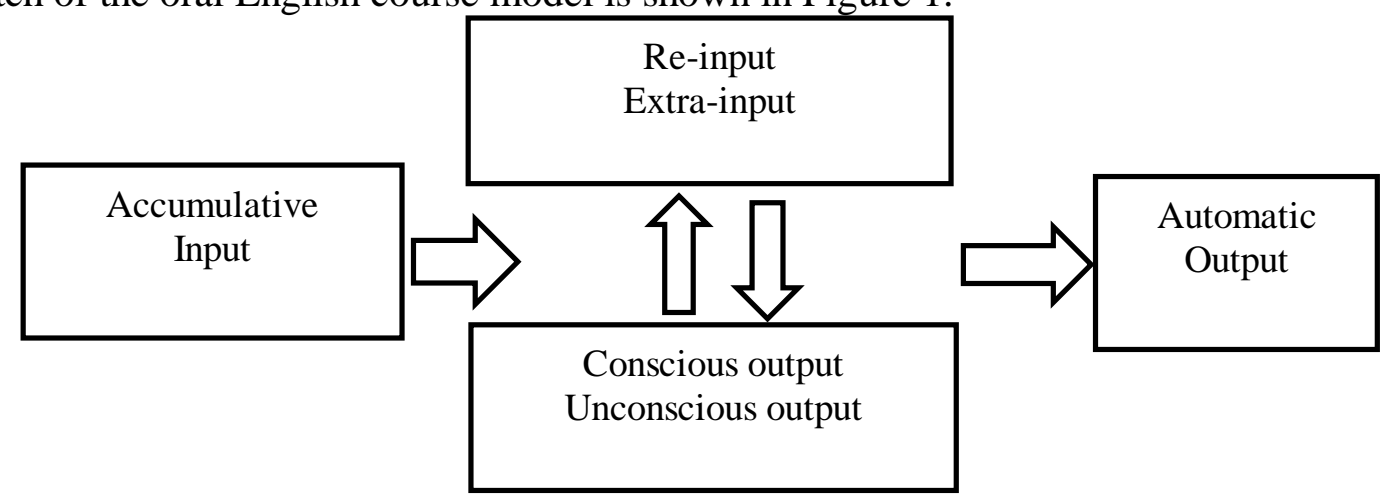

Fig.1 The sketch of Curriculum Setting on oral English course based on prefabricated chunk theory and input and output strategies

1. Accumulative Input

This first part is aimed to facilitating accumulation of prefabricated chunks. As Krashen states in his input hypothesis, we acquire by understanding language that contains structure a bit beyond our current level of competence $(i+1)$, and this process is realized under the help context or extra-linguistic information [11]. Inputting knowledge of higher levels is an accumulating process. How should this process be conducted? According to our questionnaire survey, $75 \%$ students' knowledge about English speaking countries is insufficient, which partly contributes to the mistakes when speaking English. Therefore, we suggest acquainting students with new lexical chunks by providing context and extra-linguistic information. Topic-oriented classes with multimedia teaching approaches are advocated. Teachers' consciously pointing out the lexical chunks can facilitate the formation of prefabricated chunks in students' mind and promote students' awareness of inputting lexical chunks.

2. Collaborative Dialogue

"Collaborative dialogue is dialogue in which speakers are engaged in problem solving and knowledge building" [6]. The object of this part is reinforcing the prefabricated chunks' formation in 
students' mind. Based on the understanding of collaborative dialogue, we embody this conception into 4 practices:

1. Re-input: Inputting lexical chunks that are memorized before by listening to others.

2.Extra-input: Inputting lexical chunks that are not memorized before by listening to others.

3. Conscious output: Speaking out after word-searching, word-selecting, word-collocating and grammar-processing.

4.Unconscious output: Access prefabricated chunks without conscious attention.

This 4 practices are in crossed progress instead of following a chronological order, serving as approaches to realize examining and revising. Our questionnaire survey shows that $50 \%$ of students are fund of group discussing and performing to practice spoken English. Therefore, we can refine group discussion and performance to enhance the input and output of prefabricated chunks. Irregular group discussion and improvisational performance are advocated. Teachers should provide help only by giving keywords. Discussion and performance should be timed to stimulate the output of prefabricated chunks.

3. Automatic output

The desired outcome for oral English class is developing automaticity. Swain discussed three possible functions of output in the learning process: noticing, hypothesis testing, and reflective function[8]. The first two functions are related to language accuracy, which have been included in the prefabricated chunk, while the third function is connected with fluency. The consistent, regular and successful reflections between output and grammar can generate automaticity in the operation, thereby improves the fluency of expression [12].

\section{Summary}

This paper explores the combination of prefabricated chunk theory and input and output strategies in oral English course and proposes a curriculum setting catering to English-language learners' demands. The setting in this paper is summed up as follows. First, the accumulative input part is aimed at facilitating accumulation of prefabricated chunks. Lexical chunks imparted by Teachers consciously help their formation in students' mind. The second collaborative dialogue part contains four crossed practice-Re-input, extra-input, conscious-output and unconscious-output. This process intensively trains learners' prefabrication of lexical chunks. The third part, automatic output is developed as the desired outcome of the setting. With the help of this setting, English-language learners' spoken English will have a better chance to become proficient.

\section{References}

[1]. Becker, J. The phrasal lexicon[M]. Cambridge, Mass: Bolt Beranek \& Newman, 1975.

[2]. Bolinger, Dwight. Meaning and memory. Forum Linguisricum, 1976, 1(1), p. 1-14.

[3]. Nattinger, J. R. and J. S. DeCarrico. Lexical Phrases and Language Teaching. Oxford: Oxford University Press. 1992.

[4]. Lewis M. The Lexical Approach[M]. Hove. England: LTP, 1993.

[5]. VanPatten, Bill. From input to output: A teacher's guide to second language acquisition. Boston: McGraw-Hill. 2003.

[6]. Swain, Merrill. The output hypothesis and beyond:mediating acquisition through collaborative dialogue. Sociocultural theory and Second Language Learning. 2000.

[7]. Krashen, S. D. The input hypothesis: Issues and implications. New York: Longman, 1985.

[8].Swain, Merrill .Communicative Competence:Some Roles of Comprehensible Input and Comprehensible Output in its Development [ A]. In S.Gass \&C .Madden (eds.). Input in SLA[ C]. Rowley, Mass: Newbury House, 1985.

[9]. Altenberg, B. Speech as linear composition. Proceedings from the Fourth Nordic Conference for English Studies. University of Copenhagen, 1990, p. 133-143. 
[10]. Qi Wei, Research on the Application of Chunk Theory in Oral English Teaching. Journal of Civil Aviation Flight University of China. Vol. 25 (2014) No. 4, p. 50-54.

[11]. Krashen, S. D. Principles and Practice in Second Language Acquisition[ M]. New York: Pergamon Press, 1982.

[12]. Lu Renshun.The Enlightenment of "output hypothesis" to English Teaching in China. Foreign Languages and Their Teaching. Vol. 4(2002) No. 4, p. 34-37. 